Selene Beviláqua Chaves Afonso ${ }^{1}$

Rosa Maria de Araujo Mitre ${ }^{2}$

${ }^{1}$ Serviço de Psicologia Médica, Instituto Fernandes Figueira, Fiocruz. Av. Ruy Barbosa 716, Flamengo. 22.250-020 Rio de Janeiro RJ. selene.zero@gmail.com ${ }^{2}$ Saúde Brincar, Instituto Fernandes Figueira, Fiocruz.

\section{Notícias difíceis: sentidos atribuídos por familiares de crianças com fibrose cística}

\author{
Difficult news: meanings attributed \\ by family members of children with cystic fibrosis
}

Abstract This article studied some of the meanings that difficult news assumes when transmitted by health professionals to relatives of young cystic fibrosis patients undergoing treatment at a public hospital located in the south zone of the city of Rio de Janeiro, Brazil. It is the result of qualitative research and analysis of ten narratives collected during two months in 2010. These meanings are not understood by professionals and interfere with the evolution of the illness, the coping process and the care given to the children. It has been observed that the content of the news is perceived differently depending on: The clarity with which it is transmitted to each family member; The forthright way it is conveyed without the preparation of the listener; The consideration of the context in which people live and the consequences involved; The presence of a family member when the news is delivered; and the fragmentation of information. Results indicate the need to make professionals aware of the importance of communication aspects in clinical meetings and the inclusion of this training process in the medical curriculum as well as during physicians' professional lives. It seems that in delivery of the news the family expects a balance between technical efficiency and conversational tact from professionals.

Key words Cystic fibrosis, Family, Child, Communication, Difficult news
Resumo Este artigo apreendeu sentidos atribuídos por familiares de crianças com fibrose cística sobre as noticias dificeis transmitidas por profissionais de saúde durante o tratamento num hospital público terciário da zona sul do Rio de Janeiro. Resulta de pesquisa qualitativa e análise de dez narrativas colhidas em dois meses de 2010. Supôs-se que esses sentidos são pouco conhecidos, interferem na vivência e enfrentamento do processo de adoecimento e cuidado dos filhos. Evidenciou-se que o conteúdo da notícia era percebido diferentemente segundo: a clareza com que ela era adequada a cada familiar, a forma direta de transmiti-la sem preparação do ouvinte, a consideração do contexto em que viviam as pessoas e as consequências que nele provocaria; a presença de um acompanhante no momento da notícia e a fragmentação das informações. Os resultados indicaram a necessidade de sensibilizar profissionais para aspectos comunicacionais nos encontros clínicos e inclusão dessa capacitação na graduação elou ao longo da atividade profissional. Viu-se que a notícia, embora não parecesse difícil para os profissionais podia sê-lo para familiares; que ela afeta a experiência da doença e que os familiares esperam dos profissionais equilíbrio entre eficiência técnica e competência relacional. Palavras-chave Fibrose cística, Família, Criança, Comunicação, Notícias difíceis 


\section{Introdução}

A fibrose cística (FC) é a mais importante doença hereditária autossômica recessiva que leva à morte a incidir sobre a raça branca e constitui condição crônica que pode ter longa duração, impondo-se ao indivíduo e modificando seu cotidiano em muitas dimensões. Alteram-se as relações com a família, com a sociedade, com as instituições de saúde, com os cuidadores e demais grupos sociais, assim como as crenças e os valores pessoais dos sujeitos ${ }^{1-6}$.

Nas últimas décadas as novas abordagens da doença aumentaram drasticamente a expectativa de vida dos pacientes com FC especialmente nos países desenvolvidos, mas ela permanece universalmente fatal, sendo a doença pulmonar avançada a principal causa de morte. Suas manifestações costumam ocorrer desde os primeiros meses de vida, entretanto o diagnóstico, muitas vezes, não é imediato. Diagnosticada, a FC requer tratamento intensivo e uma rotina rigorosa de cuidados.

A evolução da doença pode ser acidentada determinando hospitalizações, cirurgias, limitações físicas, dependência de tecnologia e o transplante pulmonar ${ }^{7}$. Por isso, exige que pacientes e familiares encararem vida e morte a todo o momento, de forma consciente ou não e nas atividades diárias, desde o diagnóstico ${ }^{8}$.

Nessa trajetória os pais recebem diversas notícias difíceis, ou seja, aquelas que afetam adversa e negativamente a visão de futuro de uma pessoa e seus planos9. Dependendo da forma como sejam transmitidas e de como as famílias as percebam, podem afetar a experiência com a doença e o cotidiano familiar. Neste artigo considera-se a comunicação feita por todas as categorias profissionais envolvidas no tratamento da criança já que se dá em equipe multidisciplinar.

A comunicação interpessoal continua sendo a ferramenta primária usada entre profissionais e pacientes/familiares para a troca de informações, apesar do incremento da sofisticação tecnológica para o diagnóstico e o tratamento biomédico. Ela interfere na satisfação com o tratamento, na aderência, na retenção e compreensão da informação, na capacidade de superar os desafios promovidos pela doença e na capacidade de promover a saúde ${ }^{10-15 .}$

Uma melhor comunicação não se restringe a veiculação de informações relevantes e corretas. Ela requer entendimento entre os atores considerando o ponto de vista e saberes dos usuários, propiciando o compartilhamento de responsa- bilidades nos cuidados, contribuindo para a construção de sujeitos e ampliando sua capacidade de fazer escolhas ${ }^{16}$.

Embora a boa comunicação entre profissionais e pacientes/familiares seja considerada parte da arte na medicina, ela ainda é percebida como dom ou algo que se aprende com a experiência, expondo todos os atores ao sofrimento em situações em que essas habilidades são inadequadamente empregadas ${ }^{17}$. O surgimento de instrumentos que auxiliam profissionais na transmissão dessas notícias corrobora a necessidade de preparo para essa tarefa 9 .

Em levantamento feito na Biblioteca Virtual em Saúde sobre as percepções de familiares de crianças com FC a respeito de notícias difíceis, os nove trabalhos encontrados referem-se ao suporte oferecido pela equipe de saúde na ocasião do transplante pulmonar e à implantação do rastreamento (diagnóstico precoce). Isto evidencia uma lacuna na discussão de aspectos da FC pela ótica daqueles que têm seu cotidiano atravessado pela experiência da doença crônica.

\section{Métodos}

A pesquisa qualitativa foi escolhida por permitir aprofundar a compreensão da interferência dos aspectos culturais, ambientais, econômicos, biológicos e sociais do processo de adoecimento, sob a ótica dos familiares. Contribui também para a compreensão das ideias sobre causalidade, risco, cuidados na prevenção, formas de abordar e tratar as doenças, assim como o agir e o pensar a doença e a saúde ${ }^{18}$.

O método de narrativas trata das reflexões dos sujeitos, das representações que eles elaboram de suas vivências, suas formas de pensar e agir, abarcando aspectos subjetivos, conscientes ou não, diante da doença e da saúde. Foram considerados os personagens e suas relações, o cenário em que os fatos ocorreram, o enredo e o desfecho ${ }^{19-21}$.

Como preparação das entrevistas narrativas fez-se uma exploração do campo de onde surgiram as questões exmanentes. Depois de explanar os objetivos da pesquisa e ter a autorização para gravá-las, apresentava-se a proposta disparadora da narração central pedindo que o familiar contasse a história do adoecimento da criança. Nesse processo, para garantir o fluxo da narrativa, os estímulos de encorajamento foram apenas não verbais, de forma a mobilizar o esquema autogerador ${ }^{19}$. Somente após os sinais de fi- 
nalização ou coda perguntava-se ao informante se desejava acrescentar algo mais. Desligado o gravador, se necessário, foram feitas perguntas complementares e suas respostas anotadas em diário de campo.

Os sujeitos - a mãe ou o pai da criança foram abordados na sala de espera do ambulatório do hospital a partir de prévia seleção na planilha das consultas agendadas do setor de pneumologia. Quando o casal estava presente, foi facultado a eles que escolhessem quem participaria. Aceitando participar foram levados, no mesmo dia, a uma sala reservada no hospital buscando não sobrecarregar suas rotinas e manter a privacidade desse contato. Lemos juntos os termos do consentimento livre e esclarecido que foi previamente aprovada pelo Comitê de Ética em Pesquisa da instituição. Ficou claro o compromisso com a confidencialidade das informações para a preservação do tratamento das crianças na instituição. Das doze pessoas convidadas, dois homens aceitaram participar, mas não compareceram à entrevista.

A seleção dos sujeitos seguiu as recomendações de Minayo ${ }^{18}$ de que: eles tivessem os atributos relacionados ao estudo; fossem em número suficiente para gerar informações reincidentes; com a possibilidade de inclusão de novos sujeitos, até fornecer material para uma discussão densa.

Eles foram as mães ou os pais de crianças portadoras de FC com idades entre dois e 12 anos, sem outras comorbidades e diagnosticadas há, pelo menos, dois anos, considerando-se que nesse período os pais já teriam sido expostos às notícias difíceis. $O$ fato de a pesquisadora ser profissional da instituição pareceu não inibir os entrevistados que se mostraram interessados em colaborar.

A sequência metodológica seguiu a proposta de Gomes e Mendonça ${ }^{20}$ para a análise dos aspectos estruturais da narrativa. Inicialmente buscou-se compreender o contexto das percepções dos familiares sobre as notícias difíceis através de estudos sobre o adoecimento crônico baseados em Canesqui ${ }^{1}$, Herzlich ${ }^{4}$ e Good ${ }^{3}$.

Em seguida procurou-se identificar os sentidos atribuídos às notícias difíceis, os cenários das narrativas relativos à cronicidade, os personagens, espaços, eventos mencionados e o enredo. Por fim fez-se a interlocução entre os dados gerados pelas narrativas e o referencial teórico sobre a condição crônica, resultando na síntese interpretativa.

\section{Resultados}

\section{Sujeitos}

As narrativas foram fornecidas por nove mulheres e um homem, entre 22 e 52 anos. A maioria residia na Baixada Fluminense e tinha baixa escolaridade. Apenas uma das mães tinha curso superior incompleto e outra o nível técnico na área de saúde. Cinco narradores eram casados e os demais constituíam famílias uni parentais chefiadas por mulheres. Três informantes declararam estar empregados e dois possuíam plano de saúde complementar. Duas famílias já haviam perdido um filho com FC e outra havia perdido uma criança por outra doença. Uma família tinha outro filho com câncer e outra tinha dois filhos com FC.

\section{Enredo}

Ele determinou o início, o meio e o fim da história, assim como a escolha dos eventos a serem relatados pela intencionalidade que moldou a narrativa ao longo do processo de narração ${ }^{19,21}$. Comum a todas as entrevistas e servindo de eixo para os acontecimentos está a luta pela vida da criança, sentido constatado também na pesquisa de Damião ${ }^{22}$. Todos os sujeitos, cada um à sua maneira, entregaram-se a essa guerra contra a doença e seus desdobramentos nas diversas instâncias da vida. Tanto do ponto de vista particular quanto público e social, as modificações sofridas no decorrer do adoecimento foram marcantes. O sofrimento era uma constante e a incerteza quanto ao futuro, assim como a ameaça da morte, um pano de fundo do cotidiano.

\section{Cenários}

Todas as narrativas descreveram uma peregrinação por serviços e profissionais até que as famílias chegassem ao centro de referência. Consequentemente, a obtenção do diagnóstico variou de dois meses até quatro anos o que, em muitos casos, agravou o quadro da criança, configurando um subtratamento sob a ótica da humanização, entendendo este último conceito como a valorização e a participação dos diferentes sujeitos e saberes, a construção de um modelo de atenção voltado às singularidades com uma visão integral de saúde e a oferta de melhores serviços.

Uma vez no centro de referência, onde o diagnostico é feito, as famílias descrevem uma experiência ambígua de alívio e desespero. Encontram 
a causa para a longa história de sintomas recorrentes, mas também sofrem o impacto do conhecimento sobre as consequências da FC.

A partir do diagnóstico as consultas ambulatoriais passam a ser regulares, ocorrem longas internações para tratamento de infecções e podem ocorrer intervenções cirúrgicas - como a gastrostomia. A rotina de cuidados é diária e intensa, necessitando ser supervisionada pelas mães - cuidadoras principais.

No momento da pesquisa, o serviço de referência atendia 129 crianças oriundas do estado do Rio de Janeiro. Devido às características da doença elas eram acompanhadas pelos ambulatórios de pneumologia, fisioterapia e nutrição. As internações, em geral, ocorriam na mesma instituição, exceto para as famílias portadoras de plano de saúde suplementar. A falta de um setor de emergência neste hospital causa apreensão aos sujeitos, devido ao pouco conhecimento especializado sobre a FC fora dos centros de referência, experiência que já tinham quando da busca pelo diagnóstico.

\section{Espaços de convívio}

No âmbito familiar, a FC provoca mudanças no cotidiano pelo rigor dos cuidados necessários, impedindo que a vida siga um curso considerado normal pelos narradores. As mães separadas referem pouco ou nenhum apoio dos excompanheiros e os casais que permanecem juntos têm seus relacionamentos abalados pela rotina absorvente da doença.

Nas enfermarias e ambulatórios, o convívio com outras mães vivendo a mesma situação, faz que se constituam grupos informais onde elas se apoiam mutuamente, trocando informações e experiências que parecem tentar suprir a falta de compreensão sobre a doença.

A escola é citada como um espaço onde há lugar para a normalidade. Ela tem importante papel na socialização das crianças, mas pode gerar dificuldades em razão da forma como lida com as particularidades decorrentes da doença dos alunos com FC. Poderá ser um desafio para a criança, já que será uma experiência de exposição de suas diferenças ${ }^{8,23}$.

\section{Personagens}

\section{A mãe}

As mães são as que deixam o trabalho para dedicarem-se ao filho doente, abrindo mão da função profissional ${ }^{24}$. Elas mencionam a redu- ção de sua atenção aos outros filhos e ao marido e queixam-se da sobrecarga e do desgaste emocional que experimentam diante da doença em seus cotidianos. Esse desgaste merece atenção visto que a saúde dos cuidadores principais deve ser preservada ${ }^{17}$.

\section{O pai}

Quando o casal estava separado não havia qualquer ajuda ou interesse dos parceiros. Nos casais que permaneciam juntos os homens não conseguiam ter uma relação afetiva com as crianças ou com as esposas, deixando um vazio emocional que sobrecarrega as mulheres e acrescenta aos sofrimentos já existentes o medo de perder seus parceiros ${ }^{25}$.

\section{A morte}

A morte apareceu como personagem nas narrativas. Os familiares convivem com o medo da morte da criança e, porque sabem que ela virá um dia, sentem um pesar antecipado e o medo de falhar nos cuidados, o que abreviaria a vida do filho ${ }^{8}$.

\section{Os profissionais e as notícias difíceis}

Os sujeitos não questionaram a necessidade de receberem notícias sobre o quadro clínico de seus filhos. Alguns entrevistados, inclusive, referiram alívio pelo fato de, a partir do diagnóstico correto, os filhos passarem a ter recursos técnicos para o controle dos sintomas da FC.

Entretanto, ocorreram pontos críticos na articulação entre familiares e profissionais, especialmente da categoria médica. Possivelmente por serem aqueles que dão o diagnóstico, anunciam as mudanças de estágio da doença e as novas terapêuticas para enfrentá-las. Esses profissionais foram vistos como mensageiros das notícias difíceis e receberam a maior carga das reações, conscientes ou não, dos familiares.

quando chegava perto dele [médico], eu ficava nervosa. Acho que é psicológico, né? Medo de saber mais e mais sobre a doença

Dentre outras coisas, os pais queixavam-se de não compreender a complexidade da doença de que sofriam os filhos.

Onde eu moro, meus familiares também não sabiam o que era a doença, muito menos eu... Eu até hoje não sei direito que raio de doença é essa! Os médicos fala pra mim, mas... não sei, eu nunca tinha ouvido falar.

Os depoimentos evidenciaram que a comunicação esteve na base das ações fundamentais para que o projeto terapêutico tivesse sucesso. 
Mas, a maneira como as notícias foram transmitidas gerou sofrimento aos familiares e interferiu na forma deles lidaram com as consequências da FC em suas vidas. Se, por um lado os sujeitos diziam entender que as notícias precisavam ser dadas e que o profissional precisava ser racional, por outro esperavam que as repercussões emocionais que tais notícias provocariam neles, familiares, fossem levadas em conta no momento de transmiti-las.

Não tou criticando a forma. É dito pra gente, porque infelizmente a médica não pode ser [emotiva], né? levar o lado emocional, mas eu acho que tinha que ter um consenso entre o racional e o emocional [do profissional].

As expressões "dura", "direta" ou "seca" foram frequentemente usadas para descrever a forma como as notícias foram dadas.

Assim, alguns é curto e grosso, não é? Não chega com jeitinho. A Dra. X, ela é uma que chega logo, fala logo. Não espera assim... [usando um tom suave, pausado e preocupado] 'Mãe, tem alguma coisa pra falar com você. É isso, isso e isso'.

Do ponto de vista dos pais, havia uma conjunção do conteúdo da notícia difícil com a forma como ela era transmitida que as tornava ainda piores. Através do tom da comunicação o familiar dizia perceber o grau de envolvimento dos profissionais, seu interesse, preocupação e empenho dedicados à criança e a eles próprios.

Eu fico triste por isso, porque é o jeito que a pessoa fala que magoa. A gente sofre mais. Parece que sofre mais com o jeito direto, pra você assim, chega e não senta pra conversar, já chega logo falando. Acho que o que machuca é isso.

Os familiares mostraram que gostariam que os profissionais conhecessem e considerassem suas apreensões, o contexto em que viviam e as influencias das notícias sobre ele. Era o caso da família que planejou outra gravidez na esperança de que essa criança doasse a medula para o primogênito que sofria de leucemia. No entanto, a FC da segunda filha foi um impedimento para o transplante, o que tornou a notícia exponencialmente mais difícil.

E a primeira pergunta que eu fiz [para a médica] foi essa: 'ela [paciente] vai doar a medula pro irmão?' A resposta da doutora foi seca, grossa: 'Não, nem pensar! A senhora tá maluca!'Aí começou a minha luta, não é.

Também surgiu o desejo dos familiares que os profissionais os convidassem a se sentar para receber as notícias difíceis, especialmente o diagnóstico porque o impacto causado provocavalhes, muitas vezes, mal estar físico:
Quando eu cheguei aqui, eu me lembro como fosse hoje... Eu entrei na sala, eles nem pediram pra mim sentar... E a mulher, a médica, falou pra mim: 'Mãe, sua filha tem uma doença muito grave, que não tem cura, e ela precisa ser internada às pressas'. Aquilo foi como um impacto! E quando, assim, você recebe a notícia, você tem vontade de sumir! O chão se abre! Eu pensei que eu ia vir no chão de tanto susto que eu levei.

Esperavam ainda que os profissionais, sabendo das notícias que iriam transmitir, sugerissem a presença de um acompanhante durante esses momentos. Vários familiares tiveram repercussões emocionais, como o choro incontrolável, que impossibilitou a alguns de continuarem a consulta ou uma sensação momentânea de desorientação que lhes dificultou a volta, sozinhos, para casa.

Nesse dia eu tava sozinha. E aí eu saí dali e comecei a andar na rua, pra lá e pra cá! Mas eu sabia que tinha que voltar aqui. Sempre tentando me manter consciente.

Por isso, o momento do diagnóstico - quando a incurabilidade da doença e a expectativa limitada de vida são abordadas - foi citado como o que requeria maior atenção por parte dos profissionais. Foi sugerida uma articulação com o serviço de psicologia como forma de apoio especializado imediato aos familiares.

Eu acho que na hora que o diagnóstico é feito, eu achava que tinha que ter um psicólogo. Tinha que ter uma pessoa, sabe? Assim, mais equilibrada, né? Eu estava sozinha, eu não tenho mãe, eu não tenho pai, eu não tenho mais a minha sogra... E eu fiquei sem chão, eu fiquei sem saber como passar isso pra família. Eu fiquei sem saber como lidar.

A entrega do resultado do teste do suor, que faz parte do processo de diagnóstico, caracterizou-se como uma notícia difícil pela falta de compreensão imediata do seu significado e pela fragmentação da informação.

O resultado não saía positivo ou negativo, na época: ele saía com valores, e eu não sabia qual era a referência daqueles valores. Aí dei pro meu marido, passei as referências, e ele ligou pro tio, que é pediatra. O tio disse também que não tinha noção de qual seria essa referência, que ia procurar saber, e nisso eu consegui falar com a gastro [amiga], que era a Dra X que foi falando comigo no telefone. Eu lembro que eu fui daqui até em casa aos prantos, a Dra. X, falando: 'Calma, a gente vai lidar com isso'.

A informação sobre o prognóstico provocou maior sofrimento quando feita por profissionais não especializados e que tampouco acompanhavam a criança, baseando-se em dados ge- 
néricos sobre a FC e com previsões ainda mais sombrias que as reais.

Eu trabalho com mais de vinte médicos! Meus quatro diretores são [da área de saúde]. E todos falaram que o meu filho ia morrer. Nem chegaria aos dois ou três anos. Ele [chefe] foi bem objetivo comigo. Sentou na recepção do meu trabalho e falou assim: 'Seu filho não chega aos três anos. Eu falei: 'O senhor tá me falando isso como médico ou como pai?' Ele falou assim: 'Estou falando isso pra você como médico'. Falei assim: 'Mas meu filho não é acompanhado pelo senhor'. Desculpa.

Outra dificuldade era quando, na vigência de intercorrências, os sintomas eram chamados de "normais", pois faziam parte da evolução esperada da doença. Embora não representassem risco iminente de vida, traziam preocupação ao familiar e a palavra normal dava a sensação de que o profissional estava naturalizando a situação. Ao não perceberem sinal de pesar na equipe, por vezes, os pais tomavam aquela fala como sinal de indiferença em relação à criança ou de desinteresse.

Normal como, se ela tem que fazer exames e tomar antibiótico? Aí dá vontade de dizer: normal por que não é tua filha!

Em contrapartida, outros profissionais foram citados como cuidadosos ao darem as notícias difíceis, desde a atenção em sentarem-se com o familiar até a calma com que abordavam o assunto. Para os pais, isso auxiliava a reduzir o impacto da informação, mostrando ser possível fazer diferente.

O Doutor vinha de um jeito que, por mais que seja uma notícia ruim, ele faz a pessoa ficar mais calma, né? Ele fala assim, mais sensivel. Porque tem gente que, você sabe, é direto, não quer saber a reação da mãe ou não, como é que ela vai ficar.

\section{Discussão}

A humanização engloba fatores estratégicos, tais como a formação do profissional de saúde, a relação profissional-paciente, a comunicação e o direito à informação, a hierarquia e o poder na produção de cuidados e nas tomadas de decisão, bem como os fatores psicológicos e subjetivos envolvidos nos encontros clínicos.

A comunicação entre profissionais e familiares/pacientes muitas vezes gerou conflitos. Quando os profissionais eram mais próximos e deixavam transparecer seus sentimentos genuínos de consideração, possibilitava que os familiares se percebessem como iguais. Sentiam-se valoriza- dos pela atenção que recebiam, propiciando uma parceria que os fazia tolerar melhor as notícias difíceis e os eventos ao longo do tratamento, configurando-se, assim, a oferta da melhor tecnologia combinada à humanidade nos cuidados ${ }^{26}$.

A possibilidade de os familiares compreenderem a situação da criança com FC mais integralmente dependeu de tempo para que eles assimilassem a notícia, mas, principalmente de informações inteligíveis que fossem adaptadas à capacidade intelectual de cada um e às suas limitações. Este aspecto não está objetivamente descrito por Baile et al. ${ }^{9}$ e caberia aos profissionais minimizar as consequências dessa desigualdade por meio da adequação de seu discurso técnico. Poderiam fazê-lo levando em conta as origens, o estrato social e a cultura dos sujeitos na tentativa de provê-los de todas as informações a que têm direito $^{27}$.

$\mathrm{O}$ aspecto mais citado em relação às notícias difíceis foi a forma como elas foram transmitidas. Importava, além do conteúdo, geralmente inevitável, o tom com que a notícia era dada, o momento, o lugar e a atitude do interlocutor ao fazê-lo. O conjunto de ações, conscientes ou não, compunham a totalidade da comunicação. Confirmando ser ela a ferramenta primária mais utilizada entre profissionais e usuários ${ }^{10-15,28}$.

A informação, quando dada de maneira direta ou dura, gerava sofrimento e caracterizava uma ação desumanizante. Mas, quando os profissionais foram cuidadosos e adequados ao dar notícias ou informações sobre a criança, puderam reduzir o impacto da comunicação e foram percebidos como próximos da família e sensíveis ao seu sofrimento. Essa atitude empática e os afetos positivos - que, segundo a sociologia médica, são fatores humanizantes do cuidado em saúde - têm efeito sobre a boa relação profissional-paciente e sobre a adesão ao tratamento, além de aumentar a corresponsabilidade configurando-se, assim, a oferta da melhor tecnologia combinada à humanidade nos cuidados ${ }^{28}$.

A percepção dos familiares de que os profissionais pouco valorizavam as condições preexistentes na vida dos familiares - como, por exemplo, o fato de eles terem tido um filho já falecido em razão da FC, ou outro gravemente doente de câncer, ou terem uma família uni parental e adversas condições socioeconômicas - pode refletir o reducionismo por parte do profissional, que enfatiza o indivíduo paciente e desconsidera sua família ${ }^{5,29}$. Ao contrário disso, lançar um olhar integral sobre eles levaria em conta sua condição de vida, suas histórias e as condições especiais 
preexistentes, requerendo a particularização de cada atendimento ${ }^{27}$.

Ao favorecer a autonomia dos sujeitos, é possível fortalecê-los, tirando-os da frágil condição de passivos e alçando-os à condição de direito $\mathrm{e}$ de coautores do tratamento da criança ${ }^{27,30}$. A simetria aproxima os atores, facilitando a participação dos familiares nas atividades ligadas ao tratamento. Foley ${ }^{31}$, assim como Meyer et al. ${ }^{32}$ assinalam a necessidade de que os pacientes/familiares sejam considerados parte da equipe e não um problema, porque eles detêm informações relevantes para o acompanhamento da criança e são os cuidadores principais - os que conduzem e supervisionam, no cotidiano, as orientações dadas pelos profissionais ${ }^{33}$.

O convite para que os familiares se sentassem para receber uma notícia difícil, como o diagnóstico, foi um aspecto apontado como mais que um conforto físico. Foi visto como um cuidado e o reconhecimento do impacto dessas comunicações e seus possíveis efeitos, físicos e emocionais, sobre os familiares. Portanto, o setting não se refere apenas ao local, à posição espacial dos atores e à ambiência. Ele sugere que o momento em que eles se encontrem seja composto por aspectos físicos e psicológicos somados a uma atitude empática do profissional, visando também aos passos posteriores referentes à comunicação das notícias difíceis ${ }^{8}$.

A solicitação por parte do profissional de que haja um acompanhante de confiança do familiar no momento do diagnóstico coincide com o protocolo Spikes ${ }^{8}$. Porém essa recomendação poderia ser estendida a todos os momentos que envolvem comunicações que afetem os familiares psicologicamente e/ou a aspectos fundamentais de sua vida.

As narrativas indicaram a importância de o familiar que recebe a notícia sobre o diagnóstico ter, durante o encontro, tempo suficiente com os profissionais, para obter todas as informações necessárias. Podendo esclarecer dúvidas em qualquer momento que precise e, para isso, ter fácil acesso à equipe. Idealmente, essas trocas de informações requerem um sistema bidirecional de comunicação e são muito valorizadas pelos usuá$\operatorname{rios}^{31,32,34,35}$.

A fragmentação da informação - como citada na entrega do resultado do teste do suor refere-se à desumanização pela tecnologia em que o contato do paciente/familiar com o profissional é tido como suplementar, dispensável ou até ausente, dando-se maior realce aos recursos tecnológicos que ao contato humano ${ }^{27}$.
As narrativas também mencionaram questões relativas à postura de alguns médicos que consideraram que sua posição profissional ou status social lhes permitia fazer prognósticos. De fato, os médicos citados nas narrativas não estavam autorizados a isso, por não serem especialistas da área e tampouco médicos assistentes da criança em questão, sua atitude gerou mais incerteza e dor aos familiares. Nesses casos, estava em cena a assimetria, a relação hierarquizada por uma valoração de cunho social, e a objetividade médica que, calcada em parâmetros ditos científicos, levou o médico a avançar os limites da atuação profissional ao usar inadequadamente as lógicas e as relações de poder ${ }^{27}$.

A naturalização por parte dos profissionais de sintomas e complicações esperadas na FC fez que os familiares imaginassem que, se o mesmo ocorresse com pessoas da mesma classe dos profissionais, estes teriam mais empatia e cuidariam de forma mais adequada, validando os sentimentos e a apreensão dos familiares.

Ao se classificar as pessoas por seu status ou posição na hierarquia social, ainda que de forma pouco consciente, se estaria ferindo o valor intrínseco da vida. Dessa forma, deixar-se-ia de buscar a simetria entre os interlocutores que se refere a uma atitude de respeito pela dor do outro e por suas formas de reagir às comunicações, independentemente de seu status ou posição social27.

\section{Considerações finais}

As reflexões geradas pela pesquisa apontam que a comunicação é composta por diversos aspectos que vão além da verbalização e que as opiniões dos profissionais, assim como a forma como elas são transmitidas têm um peso que afeta o ânimo dos familiares. Estes esperam dos profissionais uma capacidade de empatia que não comprometa a eficácia. Ou seja: que os profissionais possam ser técnicos racionalmente competentes e emocionalmente próximos de seus pacientes/familiares. Esperam também que haja simetria entre os atores, embora não sejam iguais uns aos outros.

Esperam ainda que os profissionais considerem que existem distintas realidades que determinam valores, comportamentos, reações e escolhas, respeitando-as como parte do compromisso profissional com a vida, sem distinção de qualquer ordem, cuidando dos pacientes/familiares dentro dos limites da biomedicina e da dignidade humana. 
Destaca-se que as notícias difíceis não são apenas àquelas sobre o diagnóstico, mas as que ocorrem durante todo o tratamento e se referem aos rumos da doença que trazem consequências à vida cotidiana e à subjetividade das pessoas. As notícias, mesmo quando não consideradas difíceis pelos profissionais, podem ter desdobramentos que alteram a rotina da família em seus planos e em seu futuro.

A comunicação interfere no cuidado com as crianças quando os familiares são menos esclarecidos quanto à forma de prestá-lo ou informados de forma menos acessível sobre a doença pelos profissionais. De forma inversa, os familiares que contam com uma melhor comunicação e uma relação humanizada com os profissionais, pautada, entre outros aspectos, pela simetria, têm a possibilidade de compreender melhor a doença e sua dinâmica. Os pais mostram-se mais capazes de encontrar meios de conviver com os compromissos do tratamento, de atendê-los e de contornar as dificuldades impostas pela doença.

No entanto, é necessário levar em conta que a maioria dos profissionais não foi preparada para valorizar os aspectos socioantropológicos e psicológicos envolvidos no encontro com os pacientes. Esses profissionais foram ensinados a li- dar com as partes do corpo em separado, com suas funções, sua mensuração e com suas reações físico-químicas. Aprenderam a reconhecer em profundidade a matéria humana, mas não foram sensibilizados para o contexto em que vivem as pessoas e seus aspectos subjetivos.

Desta forma, o exercício de examinar e refletir sobre as práticas e as atitudes em saúde, fazendo trocas com técnicos treinados para o trabalho com habilidades comunicacionais, pode aguçar a percepção dos profissionais sobre os entraves e os acertos no trato com os pacientes/familiares. Seria desejável que a comunicação recebesse tanta atenção quanto qualquer outro recurso de que se lança mão nas intervenções da área de saúde.

As narrativas sugerem a necessidade de que, nas escolas de graduação em saúde sejam incluídas cadeiras próprias das áreas de humanidades e das habilidades comunicacionais beneficiando a todos: pacientes, familiares e profissionais diante das incertezas da vida, da imprevisibilidade da natureza humana e dos limites da biomedicina. É importante que novos estudos que enfoquem a perspectiva dos profissionais sobre o processo de comunicar notícias difíceis possam ser desenvolvidos, favorecendo uma maior reflexão e adequação das atuais práticas.

\section{Colaboradores}

SBC Afonso foi responsável pela pesquisa de campo, análises e redação do artigo e RMA Mitre orientou o projeto de pesquisa e participou da elaboração e redação do artigo. 


\section{Referências}

1. Canesqui AM. Olhares socioantropológicos sobre os adoecidos crônicos. In: Canesqui AM, organizadora. Olhares socioantropológicos sobre os adoecidos crônicos. São Paulo: Hucitec, Fapesp; 2007. p. 19-51.

2. Bury M. Illiness narratives: fact or fiction. Sociol Health Illn 2001; 23(3):263-285.

3. Good BJ. The body, illness experience, and the life world: a phenomenological account of chronic pain. In: Good BJ. Medicine, rationality, and experience An anthropological perspective. Cambridge: University Press; 2008. p.116-134.

4. Herzlich C. Helth and illness on the eve of 21 st century: from private experience to the public sphere and back. Physis 2004; 14(2):383-394.

5. Kleinman A. The meaning of symptoms and disorders. In: Kleinman A.The illness narratives, soufering, healing and the human condition. United States of America: Basic Books; 1988. p 3-30.

6. Uchôa E, Vidal JM. Antropologia médica: elementos conceituais e metodológicos para uma abordagem da saúde e da doença. Cad Saude Publica 1994; 10(4):497-504.

7. Robinson W. Palliative care in cystic fibrosis. $J$ Palliat Med 2000; 3(2):187-192.

8. Jussep M, Parkinson C. "All at sea: the experience of living with cystic fibrosis. Qual Health Res. 2010; 20(3):235-264.

9. Baile WF, Buckman R, Lenzi R, Glober G, Beale EA, Kudelka AP. Spikes. A six-step protocol for delivering bad news: application to the patient with cancer. Oncologist 2000; 5(4):302-311

10. Caprara A, Rodrigues J. Relação assimétrica médico-paciente: repensando o vínculo terapêutico. Ciên Saude Colet 2004; 9(1):139-146.

11. Gouveia GC, Souza WV, Luna CF, Souza-Júnior PRB, Szwarcwald CL. Satisfação dos usuários com a assistência de saúde no Brasil. Cien Saude Colet 2011; 16(3):1849-1861.

12. Marvel MK, Epstein RM, Flowers K, Beckman HB. Soliciting the patient's agenda have we improved? JAMA 1999; 281(3):283-287.

13. Oliveira VZ, Oliveira MZ, Gomes WB, Gasperin C. Comunicação do diagnóstico: implicações no tratamento de adolescentes doentes crônicos. Psicol Estud 2004; 9(1):9-17.

14. Simpson M, Buckman R, Stewart M, Maguire P, Lipkin M, Novack D, Till J. Doctor-patient communication: the Toronto consensus statement. BMJ 1991; 303(6814):1385-1387.

15. Sucupira ACSL. A estrutura da consulta. In: Sucupira ACSL. Habilidades comunicacionais com pacientes e famílias. São Paulo: Sarvier; 2007. p. 11-46.

16. Deslandes SF, Mitre RMA. Processo comunicativo e humanização em saúde. Interface (Botucatu) 2009; 13(Supl. 1):641-649.

17. Kang T, K.Hoehn S, Licht DJ, Mayer OH, Santucci G, Carroll JM, RN, Long CM, MSW, Hill MA, Lemisch J, Rourke MT, Feudtner C. Pediatric palliative care, end-of-life, and bereavement. Pediatr Clin N Am 2005; 52:1029-1046.

18. Minayo MCS. A fase da análise do material qualitativo. In: Minayo MCS. O desafio do conhecimento: pesquisa qualitativa em saúde. São Paulo: Hucitec; 2008. p. 303-360.
19. Jovchelovitch S, Bauer MW. Entrevista narrativa. In: Bauer GG, organizadores. Pesquisa qualitativa com texto, imagem e som: um manual prático. Rio de Janeiro: Vozes; 2002. p. 91-131.

20. Gomes R, Mendonça EA, Pontes ML. As representações sociais e a experiência da doença. Cad Saude Publica 2002; 18(5):1207-1214.

21. Thompson JB. A metodologia da interpretação. In: Thompson JB. Ideologia e cultura moderna. Teoria social crítica na era dos meios de comunicação de massa. Petrópolis: Vozes; 1998. p. 355-421.

22. Damião EBC. Crenças das famílias da criança com fibrose cística [tese]. São Paulo. Escola de Enfermagem da Universidade de São Paulo; 2002.

23. Gannoni AF, Shute RH. Parental and child perspectives on adaptation to childhood chronic illness: a qualitative study. Clin Child Psychol Psychiatry 2010; 15(1):39-53.

24. Furtado MCC, Lima RAG. O cotidiano da família com filhos portadores de fibrose cística: subsídios para a enfermagem pediátrica. Rev Lat Am Enfermagem 2003; 11(1):66-73.

25. Santos MER.Crianças e doença crônica: a vida possível [tese]. Rio de Janeiro: UERJ; 2003.

26. Fortes PAC. Ética, direitos dos usuários e políticas de humanização da atenção à saúde. Saude Soc. 2004; 13(3):30-35.

27. Deslandes SF. Humanização: revisitando o conceito a partir das contribuições da sociologia médica. In: Deslandes SF, organizadora. Humanização dos cuidados em saúde: conceitos, dilemas e práticas. Rio de Janeiro: Fiocruz; 2006. p. 33-47.

28. Ayres JRC. Cuidado e humanização das práticas de saúde. In: Ayres JRC. Humanização dos cuidados em saúde conceitos, dilemas e práticas. Rio de Janeiro: Fiocruz; 2006. p. 49-83.

29. Helman CG. Interações médico-paciente. In: Helman CG. Cultura, saúde e doença. Porto Alegre: Artmed; 2003. p. 109-145.

30. Caprara A, Franco ALS. Relação paciente-médico: para uma humanização da prática médica. Cad Saude Publica 1999; 15(3):647-654.

31. Foley GV. Enhancing child-family-health team communication. Cancer 2006; 71(10):3281-3289.

32. Meyer EC, Ritholz MD, Burns JP, Truog RD. Improving the quality of end-of-life care in the pediatric intensive care unit: parents' priorities and recommendations. Pediatrics 2006; 117(3):649-657.

33. Ong LML, Haes JCJM, Hoos AM, Lames FB. Doctor-patient communication: a review of the literature. Soc Sci Med 1995; 40(7):903-918.

34. Donabedian A. Evaluating the quality of medical care. Milbank Mem Fund Q; 2005; 83(4):691-729.

35. Afonso SBC. Notícias difíceis: sentidos atribuídos pelos familiares de crianças com fibrose cística [dissertação]. Rio de Janeiro: Fundação Oswaldo Cruz; 2011.

Artigo apresentado em 18/07/2012

Aprovado em 20/09/2012

Versão final apresentada em 05/10/2012 